\title{
PROCESOS DE ENSEÑANZA EN ESCUELAS RURALES MULTIGRADO DE MÉXICO MEDIANTE COMUNIDADES DE APRENDIZAJE ${ }^{1}$
}

\author{
Teaching processes in multigrade rural schools in Mexico through \\ learning communities
}

\author{
Diego Juárez Bolaños \\ e-mail: diego.juarez@ibero.mx \\ Erik Said Lara Corro \\ e mail: erik_lara@outlook.com \\ Universidad Iberoamericana. México
}

\begin{abstract}
RESUMEN
El artículo analiza los procesos de enseñanza desarrollados en dos escuelas primarias rurales multigrado en México, a partir de la implementación de un nuevo modelo pedagógico inspirado en el concepto de Comunidades de Aprendizaje. De manera inicial, se describen las características generales del modelo y del organismo estatal que lo desarrolla, para después destacar las fortalezas y limitaciones observadas durante la implementación del modelo en las escuelas seleccionadas. Entre las fortalezas se identifican el fomento de procesos de autonomia y el desarrollo de competencias investigativas y de expresión oral y escrita en los alumnos. Como limitantes, se señala la convivencia de prácticas innovadoras y tradicionales en las aulas, además de la pobre dotación de recursos por parte del Estado hacia la educación en las poblaciones rurales.
\end{abstract}

PALABRAS CLAVE: educación rural; multigrado; comunidades de aprendizaje; México.

\section{ABSTRACT}

This article analyzes the teaching methods developed in two primary rural multi-grade schools in Mexico, based on the implementation of a new pedagogical model inspired by the concept of Learning Communities. The text examines the general characteristics of the model, and of the state agency that develops it, and also highlights both the strengths and limitations observed during the implementation of the model in the selected schools. Among the strengths is the promotion of autonomy processes and the development of investigative skills and also oral and written communication in students. The limitations are noted as the coexistence of innovative practices along with traditional classroom practices, as well as the poor provision of resources by the state towards education in rural communities.

KEY WORDS: rural education; multi-grade; learning communities; Mexico.

Recibido/Received: 16/03/2017 Aprobado/Aproved: 22/12/2017

Cómo referenciar este artículo / How to reference this article:

Juárez Bolaños, D. \& Lara Corro, E. S. (2018). Procesos de enseñanza en escuelas rurales multigrado de México mediante Comunidades de Aprendizaje. Tendencias Pedagógicas, 31, 149-164. doi: http://dx.doi.org/10.15366/tp2018.31.009

\footnotetext{
${ }^{1}$ El presente artículo proviene del proyecto de investigación titulado "Asesoría para fortalecer el Modelo ABCD desde la perspectiva de su aporte al multigrado", financiado el Consejo Nacional de Fomento Educativo. Agradecemos los apoyos de esta institución para el desarrollo del estudio.
} 


\section{INTRODUCCIÓN}

Creado a inicios de la década de los setenta, el Consejo Nacional de Fomento Educativo (Conafe) es un organismo gubernamental que ofrece servicios de educación básica a niños y jóvenes que habitan en pequeñas localidades rurales de México, la mayoría de ellas menores a 500 habitantes. Ello se realiza a través de programas de educación inicial, preescolar, primaria y secundaria (Mejía y Martín del Campo, 2016; Urrutia, 2014; Juárez, 2009; Guerra y O’Donnell, 2000).

En sus inicios, se planeaba que Conafe desarrollase sus labores de manera temporal y extraordinaria, a fin de incrementar los indicadores de cobertura educativa en el país. Sin embargo, a más de 40 años de ser creada, esta institución se ha consolidado como una modalidad permanente. Durante el ciclo escolar 2014-2015, el Consejo trabajó en más de 34,000 escuelas preescolares, primarias y secundarías en prácticamente todo el país, con la única excepción de la Ciudad de México. A sus planteles asistieron 320,199 alumnos y en ellos laboraron 60,057 docentes (INEE, 2016). Todas las escuelas trabajan mediante la modalidad de multigrado, es decir, los maestros atienden a estudiantes de más de un grado escolar en el mismo tiempo y espacio.

A partir del ciclo escolar 2016-2017, el Conafe ha implementado un nuevo modelo pedagógico llamado Aprendizaje Basado en la Colaboración y el Dialogo (Modelo ABCD). Éste sigue "una metodología pedagógica de atención personalizada en la que cada estudiante aprende a su ritmo y desde su propio interés, estudiando y compartiendo una serie de temas que conforman el currículo de la educación comunitaria, dichos temas constituyen los aprendizajes clave y se organizan por lenguajes académicos en los campos formativos" (Conafe, 2017). El modelo se inspira en principios planteados en el concepto de Comunidades de Aprendizaje. pretende,

De acuerdo con Coll (2004), en las Comunidades de Aprendizaje se

- Elaborar el conocimiento de manera colectiva.

- Facilitar el aprendizaje autónomo y autorregulado.

- Fomentar la libertad para seleccionar actividades de aprendizaje por parte de los participantes, quienes deben percibirlas como relevantes y significativas.

- Desarrollar estrategias didácticas sistemáticas.

- Fomentar el aprendizaje colaborativo, mediante el cual se facilite el que todos los participantes puedan compartir aprendizajes.

- Dejar de lado el currículo tradicional organizado por materias aisladas, adoptando enfoques globalizadores e interdisciplinarios.

- Priorizar la profundidad sobre la extensión de los aprendizajes.

- Utilizar recursos externos en las actividades que fomenten los aprendizajes, tales como la participación de alumnos de otras escuelas o de habitantes de las comunidades.

- Establecer altos niveles de diálogo, interacción y comunicación entre los participantes.

Dentro de las instituciones educativas que atienden a las poblaciones rurales en México, el Conafe es la que menos atención ha recibido por parte de la investigación y la academia. En este sentido, además de la relevancia que 
tiene su labor en localidades históricamente olvidadas y marginadas y que en sus aulas se desarrolla un nuevo modelo pedagógico, el objetivo del presente artículo es analizar los procesos pedagógicos desarrollados mediante el Modelo $A B C D$ en dos escuelas primarias multigrado.

Las autoridades del Consejo ayudaron a seleccionar las escuelas examinadas, bajo la consideración de que en ellas se desarrollaban prácticas pedagógicas significativas alrededor del Modelo. En el trabajo de campo se ralizaron observaciones y videograbaciones de clases entre los meses de diciembre de 2016 y febrero de 2017. Además, se entrevistó a los docentes. Para ello, elaboramos guiones de observación y entrevistas, las cuales fueron transcritas y sistematizadas con el apoyo del programa de análisis cualitativo ATLAS.ti.

El artículo se divide en tres partes: en la primera describimos las características generales del Consejo Nacional de Fomento Educativo y del modelo de Comunidades de Aprendizaje. Posteriormente, examinamos los datos obtenidos en campo, para concluir con un apartado de reflexiones finales.

\section{CONAFE Y COMUNIDADES DE APRENDIZAJE}

Mediante el argumento de que en México no existen suficientes docentes profesionales para laborar en las escuelas establecidas en las pequeñas y dispersas comunidades rurales, desde sus orígenes el Conafe ha desarrollado sus programas a través de servidores sociales. Estas figuras educativas son llamadas Líderes de Educación Comunitaria (LEC), anteriormente conocidos como Instructores Comunitarios, y son jóvenes egresados de secundaria o del nivel medio superior, incluso con estudios incompletos de carreras universitarias, quienes realizan su servicio social impartiendo clases durante uno o dos ciclos escolares. Durante ese periodo radican de manera permanente en las localidades donde laboran. Una vez que concluyen su servicio social reciben una beca por parte del Estado para continuar sus estudios.

El Consejo también cuenta con figuras educativas llamados Capacitadores Tutores (CT), Asistentes Educativos (AE) y Asesores Pedagógicos Itinerantes (API), quienes desarrollan tareas de apoyo, supervisión y asesoría pedagógica dirigidas hacia los LEC (Conafe, 2017). Los dos primeros actores están involucrados en la formación inicial y continua, así como en el acompañamiento pedagógico y el apoyo administrativo a los Líderes de Educación Comunitaria. El API visita de manera periódica algunas escuelas seleccionadas para atender de forma personalizada a los estudiantes con más bajo rendimiento escolar, en coordinación con los LEC y los padres de familia (Conafe, 2012 y 2017).

Para facilitar el trabajo multigrado en las aulas, los alumnos no se organizan por grados escolares, sino por niveles. Existen tres niveles y cada uno de ellos equivale a dos grados de la escuela primaria. Los estudiantes realizan juntos el mismo programa de estudios y es deseable su permanencia en el nivel durante dos ciclos escolares.

Las familias de los estudiantes sostienen los servicios educativos mediante el otorgamiento de la alimentación y hospedaje a los LEC durante su 
permanencia en las comunidades. También participan activamente en actividades de apoyo escolar y en la construcción y mantenimiento de las escuelas.

A finales de la década de los 80 y con el apoyo del Departamento de Investigaciones Educativas del Cinvestav, Conafe creó una propuesta pedagógica específica para escuelas rurales multigrado, a través de una serie de materiales titulados "Dialogar y Descubrir". Éstos incluían manuales para docentes y fichas y cuadernos de trabajo dirigidos a los alumnos. Los materiales estaban diseñados para que los niños pudiesen trabajar de forma independiente cuando el docente no los atendiera de forma directa. Se promovía el aprendizaje y trabajo grupales, partiendo de perspectivas constructivistas.

Un estudio realizado sobre el desarrollo del modelo Dialogar y Descubrir (Juárez, 2009) encontró que en algunas primarias el uso de los manuales no fue promovido de manera eficaz y que tales materiales no eran suficientemente aprovechados por los docentes. Esto provocaba que parte de las clases fuesen improvisadas y poco dinámicas. Algunos alumnos eran escasamente reflexivos en clase, realizaban mecánicamente las operaciones básicas de matemáticas sin reconocer en qué tipo de problemas las debían utilizar como herramientas de solución, además de presentar dificultades de comprensión lectora. En las escuelas incluidas en el citado estudio, la enseñanza de la lectoescritura se desarrollaba mediante estrategias alfabético-silábicas, las cuales incluían la elaboración de planas y la copia de textos, dejando de lado el método constructivista que fomentaba el Conafe en sus manuales. Asimismo, se desvalorizaba el desarrollo de actividades artísticas, tecnológicas y las relacionadas con temas de salud y educación física.

Mejía y Martín del Campo (2016) destacan que, en general, los estudiantes atendidos por Conafe tienen tasas mayores, en relación al resto de alumnos mexicanos, en repetición escolar y eficiencia terminal, además de menores logros en las pruebas estandarizadas nacionales.

El Modelo ABCD, el cual sustituyó a Dialogar y Descubrir, se inspira en Comunidades de Aprendizaje, concepto desarrollado durante la segunda mitad del siglo XX (Coll, 2001; Torres, 2001; Cámara, Rincón, López, Domínguez y Castillo, 2004; Mingorance y Estebaranz, 2009). Comunidades de Aprendizaje se puede definir como una "metodología del aprendizaje por cuenta propia basado en el interés, el aprendizaje eficaz y personalizado [...] la superación de la tradicional ruptura entre diseño y ejecución [...] la capacitación para leer información y navegar sin cartabones curriculares prescrito, la rendición de cuentas y la demostración de lo que se ha aprendido" (Latapí, 2004, pp. 9-10). El término comunidad atiende "la dimensión ética de la relación que se establece entre maestro y aprendiz y entre aprendices que comparten lo que saben y pasan a ser tutores de otros compañeros en el salón de clase" (Cámara, 2008, p. 27).

Mediante el Modelo ABCD se intenta desarrollar procesos de enseñanza mutua en las aulas, a través de la atención personalizada hacia los estudiantes y la construcción colectiva de aprendizajes donde se fomenten relaciones de diálogo, confianza, colaboración y solidaridad. Se pretende que los alumnos aprendan a aprender, aprendan a convivir y logren el dominio de temas 
centrales de la educación básica, tales como la comprensión lectora, razonamiento matemático, escritura y expresión oral. Los contenidos del mapa curricular de nivel básico se agrupan en Unidades de Aprendizaje Autónomo y los procesos de enseñanza siguen cinco momentos (Conafe, 2016):

1. Se elige un tema a abordar, el cual se encuentra en alguna Unidad de Aprendizaje.

2. El alumno desarrolla estrategias para profundizar sus conocimientos del tema elegido.

3. Se demuestra lo aprendido frente a los compañeros, docentes $y / 0$ padres y madres de familia.

4. Se registra el proceso de aprendizaje.

5. El estudiante tutora a algún compañero con respecto al tema aprendido.

Inspirado en Comunidades de Aprendizaje, durante el periodo 1997- 2003 el Conafe desarrolló el programa Centros de Posprimaria Comunitaria Rural, el cual ofreció estudios de nivel secundaria a adolescentes, jóvenes y adultos de localidades rurales (López y Rincón, 2003). Posprimaria promovía que los estudiantes aprendieran por cuenta propia a través del Método de Aprendizaje por Cuenta Propia (MACP), el cual implicaba el acceso a medios de información y el desarrollo de procesos de tutoría. De esta manera, se pretendía que el alumno,

descubra su propio interés, confía en su capacidad, valora lo que sabe y lo aprovecha para entender, se siente capaz de aprender lo que desconoce, toma en cuenta el contexto de los materiales de estudio (la perspectiva, la intención, la temporalidad), dialoga con los autores, se esfuerza por entender siempre, toma distancia de lo que estudia, controla su proceso de aprendizaje, busca apropiarse del conocimiento, se autoevalúa, se entusiasma por seguir aprendiendo con autonomía, demuestra públicamente lo aprendido y acepta que el conocimiento es provisorio (López y Rincón, 2013, p. 51).

Además de aprender por cuenta propia, se buscaba que los estudiantes eligieran libremente los temas que les interesaban con la finalidad de generar procesos de apropiación, siguiendo estrategias de asistencia y certificación escolar flexibles.

En una publicación donde se analizó la implementación del programa de Posprimaria (Pieck, 2006), se ofrece un panorama de las tensiones generadas entre los supuestos del modelo con los contextos, los actores y las instituciones involucrados durante su implementación. El autor identificó como retos del programa los siguientes:

- Necesidad de fortalecer la capacitación y formación tanto en conocimientos básicos de los docentes (redacción, comprensión lectora), como en sus competencias como facilitadores del aprendizaje y asesores de estudio, ya que la metodología de Posprimaria no era sencilla ni de fácil asimilación.

- Flexibilizar el Método de Aprendizaje por Cuenta Propia de modo tal que no se implementase como una serie de pasos a seguir, sino como estrategias.

- Necesidad de fortalecer el equipamiento e infraestructura de los centros escolares, enfatizando el enriquecer los materiales de investigación disponibles, a fin de que existiesen variedad de ellos que abordasen diversos temas desde distintos ángulos, sumado ello a utilizar materiales generados en las propias comunidades. 
- Necesidad de clarificar las vinculaciones del modelo con los procesos de desarrollo comunitario.

Además, Pieck destacó que la libertad por elegir los temas a aprender por parte de los alumnos en ocasiones se veía desplazada por la necesidad de abordar ciertos contenidos requeridos por los planes de estudio para certificar los estudios secundarios: "uno de los retos claves para el proyecto es cómo lograr que los estudiantes certifiquen aprendiendo por su cuenta, guiados por el interés y logrando aprendizajes valiosos (op. cit., p. 142).

Como aspectos favorables del programa, el autor identificó la existencia de apoyos para los docentes, como las figuras de los asesores itinerantes; el papel formador en los instructores de las reuniones mensuales de capacitación a las que asistían; el que se fomentase el aprendizaje independiente en maestros y alumnos; el haber contribuido a procesos de retención y reincorporación de matrícula escolar en zonas rurales; el haber fortalecido procesos de participación comunitaria en actividades escolares y el haber logrado que las Delegaciones Estatales del Consejo se hubiesen involucrado en el diseño y desarrollo del programa.

Otra investigación sobre Posprimaria la elaboró Turner (2004). Como puntos favorables del programa identificó la capacitación de los docentes, tanto la inicial, como la mensual y las visitas de agentes a los centros escolares por parte de agentes de apoyo, como asesores y asistentes educativos. Además, reconoció que el programa tuvo resultados educativos innovadores: "Al completar tres años el Proyecto, los instructores, los equipos delegacionales y el equipo central han acumulado experiencias diversas en el campo educativo y están desarrollando prácticas sobre aprendizaje por cuenta propia y estudios independientes" (p. 44). Sugierió poner énfasis en los procesos de selección y capacitación docente, en la dotación de recursos (infraestructura, materiales didácticos, libros) a los centros educativos, además de buscar alternativas para aumentar la comunicación para que todos los participantes en el Proyecto tuviesen acceso a las experiencias de otros actores relacionados.

Como aspectos de mejora del programa, Turner destacó que su implementación era menos abierta que lo que postulaba en los documentos oficiales; que las limitaciones en los recursos existentes en las escuelas no favorecían en desarrollo del programa y que en los procesos de evaluación de aprendizajes existía una tensión entre el desarrollo de una metodología flexible y las formas tradicionales para calificar.

\section{DESARROLLO}

Los datos que nutren el artículo provienen del trabajo de campo desarrollado en un par de primarias rurales multigrado:

- Escuela 1, localizada en el municipio de Mexquitic de Carmona, Estado de San Luis Potosí. Tridocente. Atienden a 34 alumnos: 13 de Nivel I, 10 de Nivel II y 11 de Nivel III. Cada docente trabaja con un Nivel.

- Escuela 2, localizada en el municipio de Singuilucan, Estado de Hidalgo Unitaria. Atiende a 8 alumnos: dos de Nivel I, cuatro de Nivel II, y tres de Nivel III.

Observamos que al inicio de las clases se desarrollan dos actividades: la lectura de un diario de clases por parte del estudiante quien lo hubiese 
redactado un día antes y la lectura de algún cuento procedente de la biblioteca escolar. Posteriormente, se trabajaba con alguna de las Unidades de Aprendizaje Autónomo (UAA) que se hubieran propuesto para ese mes. Tal elección no es libre: son las autoridades estatales quienes establecen qué UAA se abordarán en las escuelas. Esto marca barreras a uno de los fundamentos establecidos en el modelo Comunidades de Aprendizaje: la libre elección por parte de los alumnos de los temas a abordar de acuerdo a sus intereses, conocimientos, experiencias y expectativas. Ello podría ser una limitante en la implementación del Modelo en un sistema educativo que otorga poco margen de acción a la autonomía escolar, a la selección de contenidos curriculares y al desarrollo de procesos de evaluaciones contextualizadas y no estandarizadas.

Durante el abordaje de las UAA en ocasiones se desarrollaban procesos que poco aportaban al desarrollo de conocimientos y habilidades del alumnado. Nos referimos a actividades de copia de textos que proponían los docentes a los estudiantes. Una vez que los alumnos ubicaban los propósitos general y específico de los temas que abordarían y de haber localizado en qué nivel del trayecto formativo se ubicaban, los LEC solicitaban que tal información fuese copiada en sus libretas.

Las UAA establecen actividades llamadas Desafíos, las cuales deberían ser desarrolladas y profundizadas a través del trabajo autónomo de los alumnos. Ello implicaría desplegar procesos de búsqueda de información, su procesamiento y contraste con las ideas iniciales. Sin embargo, las bibliotecas de las escuelas observadas contaban con materiales limitados, tanto en cantidad, como en diversidad en los niveles de complejidad y de perspectivas en el abordaje de los temas. Ningún aula contaba con internet y los recursos tecnológicos disponibles eran limitados. En las comunidades rurales existen múltiples fuentes de información, más aún, donde los conocimientos llamados tradicionales han sido históricamente desvalorizados por las escuelas. Ello invita a desarrollar acciones para acercar tales saberes a las actividades escolares, a través de la participación activa de miembros de las localidades en diversas actividades. Al mismo tiempo, y tal como lo señalaron Pieck (2006) y Turner (2004) hace más de una década, el Estado debería incrementar la inversión dedicada a la mejora de la infraestructura y equipamiento de las escuelas rurales atendidas por el Conafe, como una cuestión básica de equidad educativa.

El siguiente testimonio destaca las dificultades que enfrentan los LEC durante el trabajo con las UAA,

La primera vez que abordé dos Unidades de Aprendizaje me dije: "Pues separo a los alumnos, como me lo maneja el Modelo: a unos niños les doy un tema y a otros niños otro tema para que luego entre ellos se cambien el tema y se tutoren". Pero se me hizo muy difícil porque hay niños más pequeños y necesitan más atención y ya iba con unos y me decían "Maestra, es que siempre les hace más caso a ellos y a nosotros no" y ahí voy con los otros, "Maestra, ¿por qué están haciendo aquella cosa y yo no estoy haciendo lo mismo que ellos?". Entonces había muchas preguntas y se me hizo complicado esa vez que lo manejé así. Tenía unos niños adentro del salón, otros los puse afuera porque se distraían (...). Se me hizo complicado y ya después les digo: "No, qué les parece niños, voy a trabajarlo en conjunto, a todos les doy un tema, todos parejos". Porque también veía que a lo mejor no comprendían bien un tema, por estar pensando en lo que hacía el compañero, no hacían lo tenían que hacer, entonces no 
comprendían el tema y dije: "Mejor todos juntos y siento que así lo van a entender mejor" (LEC, SLP).

Una vez que los estudiantes culminaron los Desafíos, realizaron procesos de reflexión para identificar los procesos que habían seguido en el tratamiento de los temas y, luego, prepararon la demostración pública donde presentaron frente a sus pares y otros actores lo realizado en la actividad y en algunos casos lo que aprendieron. Cada grupo produjo diversos textos y relatos que fueron socializados en las demostraciones públicas, que tienen la finalidad de socializar las experiencias de aprendizaje, aunque en la mayoría de los casos observados no se provocaron espacios de discusión de lo que se presentó. Durante las demostraciones se utilizaron figuras, imágenes y objetos, como recursos que daban sentido a los contenidos.

Finalmente, se construyeron relaciones tutoras con otros alumnos 0 madres de familia. El Modelo ABCD destaca la riqueza que pueden tener tales relaciones entre estudiantes de diversas edades, sin embargo, las observaciones realizadas en clases permitieron valorar que tal potencial es desaprovechado: la mayor parte de las tutorías se realizaron entre alumnos de similares edades, dejando de lado actividades que permitieran el intercambio de ideas entre estudiantes de diversos niveles. Una docente narra su experiencia con respecto a las relaciones tutoras,

Al momento de la tutoría entre ellos les dije: "Ahora ustedes van a ser sus maestros entre ustedes mismos". Y ya bien emocionados al principio, me decían: "Maestra entonces, ¿yo le puedo decir que no se pare?" (...) Y ya entre ellos se empezaron a tutorear y los más grandes sí lo comprendieron, los de segundo grado fue como de "Ah ya entendí". En cambio, los más pequeños yo les decía: "Mira, dile esto, dile que va a hacer una investigación, va a hacer un dibujo y de ahí va a escribir o a sacar un dibujo de lo que entendió" (LEC, SLP).

Observamos que en la relación tutora se establecieron pautas de interrogación que guiaron a la construcción de lógicas discursivas distintas a las Unidades de Aprendizaje Autónomo, pero éstas permanecían como una referencia en la práctica pedagógica de los tutores y docentes. La mayor riqueza de las relaciones tutoras radicó en la manera como cada grupo asumió las actividades encaminadas a estudiar las UAA y a motivar la participación de sus tutorados. En esa estructura de interacción se abrieron espacios para intervenciones más diversas. Sin embargo, algunos tutores siguieron los textos con una lógica discursiva vertical, como si de un recetario se tratara. Algunos alumnos reprodujeron actitudes "docentes" en la interacción con sus pares. Estas situaciones en ocasiones provocaron ciertas ritualizaciones del proceso tutor que condujeron a caminos tradicionales de enseñanza. De ahí que el uso de la copia y el dictado fueron una constante. También se utilizaron otros textos de apoyo como libros de la biblioteca, diccionarios o revistas que se aprovecharon en las situaciones de enseñanza.

La producción de textos varió en función de las pautas de interacción y la lógica discursiva que se estableció entre el tutor y el tutorado. Algunos de los primeros establecieron momentos para la escritura, desplegaron una gama de estrategias de interrogación que llevaron a producir respuestas cortas y elaboradas, así como momentos de silencio por parte de sus tutorados al no 
tener clara alguna respuesta a tales preguntas. Ante estas situaciones, los tutores tendieron a redefinir sus preguntas o problemas en función de la reacción del tutorado.

Algunos procesos de tutoría entre adulto y niño mostraron el compromiso por parte de las madres por lograr que su tutorado se acercase a la comprensión de los desafíos que se le planteaban. El diálogo fue más fluido cuando la tutoría se construyó entre adultos- alumnos, que entre pares de estudiantes. Los docentes apoyaron e intervinieron en algunos de los procesos de tutorías, centrando su atención en los grupos formados por niños que aquellos que estuviesen a cargo de alguna madre de familia. En general, las intervenciones docentes durante el desarrollo de las tutorías fueron breves y en ocasiones realizaron alguna pregunta abierta a los niños para saber "cómo van" - para apoyar a aquellos estudiantes que presentaban alguna dificultad en el desarrollo de la actividad, pero tal atención parecería ser insuficiente para generar o reforzar procesos de profundización en el abordaje de los contenidos.

Examinemos la siguiente secuencia de interacción que ilustra un proceso de relación tutora entre una madre de familia y un niño de segundo grado, y las relaciones que se construyen en torno a las unidades de aprendizaje. La tutora leyó el contenido al niño y después le solicitó que copiara el texto de la presentación de la unidad. Luego, buscó explicarle el siguiente contenido:

Karla y Raúl cumplen años el mismo día, 15 de abril. Karla está en México y Raúl viajó con su familia a Japón, pero ellos siguen comunicándose. Karla le habló a su amigo el 15 de abril a las 11 de la mañana para felicitarlo. Raúl se puso muy contento, aunque ya estaba durmiendo y le comentó que su cumpleaños había sido ayer. ¿Cómo es que Raúl cumplió un día antes que Karla? (en Pensamiento matemático, Conafe, 2016, p. 87).

Después, se construyó la siguiente interacción:

Tutora: A ver $\mathrm{m}^{\prime}$ ijo, el contenido trata de por qué Karla y Raúl cumplen años el mismo día y viven en diferentes países. Es que Karla le habla, ella vive en México y le habla a Raúl (mira el contenido del libro), entonces las horas son diferentes; entonces, para Raúl ya había cumplido un día antes y Karla le habló el mero día del cumpleaños. Ahora, ¿dónde está Japón? ¿Sí lo alcanzas a distinguir o voy por el otro [globo terráqueo] más grande?

Ao: $\quad$ (Asiente con la cabeza)

Tutora: ¿Sí lo alcanzas a distinguir o no?

Niño: $\quad$ Aquí está Japón (ubicando en el globo terráqueo)

Tutora: ¿Seguro?

Niño: (Asiente con la cabeza)

[secuencias omitidas]

Tutora: Ahí está Japón. Entonces, ¿por qué crees tú que Karla cumple años?

Niño: (Observa el libro y el globo. Se percibe confundido)

Tutora: A ver, ¿qué dice? (mira el libro y lee en voz alta una pregunta). “¿Cómo es que Raúl cumplió un día antes que Karla?». ¿Tú por qué crees que cumplió un día antes? 
Niño: $\quad$ Porque va dando vueltas (señala el globo)

Tutora: Ajam, ¿y cómo se le llama a eso que va dando vueltas?

Niño: Uhm, ¿va girando?

Tutora: Girando. ¿Cómo más se conoce? Aparte de girar, ¿cómo más?

Niño: (Se percibe pensativo)

Tutora: ¿Con qué otro nombre se conoce aparte de girar?

Niño: (Mira el libro) No me acuerdo

[secuencias omitidas]

Tutora: Aquí está México y aquí está Japón [...], supongamos que éste, que está muy pequeño, es nuestro planisferio. Nada más que aquí nosotros tenemos por mitad, ¿sale?

Niño: $\quad$ (Señala la ubicación de México)

Tutora: Ajá, por mitad. Está abarcando México y está así, mira, así está México. Entonces, si lo tenemos por mitad, se supone que en México, ¿por qué le habló Karla a Raúl el mismo día que cumplían años? ¿A qué hora le habló Karla?

Niño: $\quad$ A las once de la mañana

Tutora: Le habló Karla a las once de la mañana. Entonces, ¿México qué era?

Niño: De día

Tutora: De día. Entonces, aquí en México está el Sol, ¿y en Japón?

Niño: Ya era de noche

Tutora: Entonces, ¿dónde está Japón? Sí aquí [México] es de día, ¿dónde está Japón?

Niño: ¿Aquí? (señala la otra parte del planisferio)

Tutora: (Utiliza el globo terráqueo) Aquí es México y si avisamos ya es de día, porque la posición indica que está el Sol, ¿no? Pero si tú dices que «porque gira». A ver, la vamos a girar. Recordemos que aquí estamos (señala la ubicación de México). Ahora, aquí está el Sol (utiliza una bola de papel), ¿sale? Entonces, ¿dónde está Japón si acá está México?

Niño: ¿ ¿Por aquí? (señalando una zona cercana a Australia)

Tutora: (Corrige) Por aquí está más o menos. Entonces, ¿por qué gira? Entonces, ¿a qué hora crees que haiga sido allá en Japón si en México eran las once de la mañana?

Niño: ¿Las diez?

Tutora: Pero, ¿cuántas horas tiene el día?

Niño: Doce del día y doce de la noche

Tutora: Entonces, sí le habló a las once, ¿a las diez era todavía de...?

Niño: ¿De día?

Tutora: Entonces no pudo ser a las diez. ¿Tú a qué horas crees que era allá? Si Karla le habló a las once de la mañana, y Raúl le dice que ya había cumplido años un día antes, ¿por qué crees tú que haiga pasado eso? 
Niño: No sé. ¿Sí cumplen años los dos?

Tutora: Sí cumplen años los dos el mismo día, ¿por qué crees que pasó eso o qué crees que pasó ahí?

Niño: ¿Le cambiaron las horas?

Tutora: Uhm, ¿se cambiaron las horas? ¿Cómo se cambiaron las horas?

Niño: $\quad$ Porque si dijo que allá en Japón era de noche y aquí [en México] era el Sol, por eso cambió

Tutora: ¿Tú crees que por eso cambió?

Niño: (Asiente con la cabeza)

En este ejemplo destacamos la iniciativa de la tutora de incluir en la interacción diversas pistas para acercar al niño a lo que ella quiere que aprenda: el movimiento de rotación de la Tierra. Para ello, la tutora formula diversas preguntas abiertas al niño, que pretenden acercarlo a la comprensión de por qué Raúl cumplió años antes que Karla, si el cumpleaños de ambos es el mismo día. Ante esas formulaciones, la explicación del niño de ese fenómeno es porque esto va dando vueltas, refiriéndose implícitamente al movimiento de rotación de la Tierra. Sin embargo, la tutora pretende que el niño nombre la noción de "rotación": ¿y cómo se le llama a eso que va dando vueltas?, ¿cómo más se conoce?, ¿con qué otro nombre más se conoce?, a lo que el estudiante le responde: no me acuerdo.

Ante la necesidad de que el alumno nombre "correctamente" el fenómeno (i.e., rotación), la tutora busca "enseñar cómo se explican los fenómenos físicos desde el punto de vista de la ciencia, esto es, lo que 'realmente sucede' o lo que son los hechos para la ciencia" (Candela, 2006, p. 805). No obstante, ella no niega la validez de lo que el niño dice, sino que las retoma para guiar la construcción del conocimiento. Además, en este intercambio observamos que el niño incorporó sus explicaciones a partir de sus conocimientos de sentido común; es decir, él explica que ese fenómeno natural ocurre "porque va dando vuelta la Tierra". Son saberes que moviliza a partir de lo que él ha aprendido en otras clases y en los distintos ámbitos de la vida cotidiana. En este sentido, la tutora utiliza esos conocimientos para acercarlo a lo que ella quiere que aprenda.

Con relación a nuestra discusión sobre las formas de trabajo en el Modelo $A B C D$, en esta interacción en la actividad el niño se acercó a la comprensión los fenómenos de rotación de la Tierra y los cambios de horario. Es decir, en el proceso la tutora formuló una serie de preguntas abiertas, explicaciones y demostraciones físicas (i.e., globo terráqueo y planisferio) para guiar al alumno hacia la comprensión del tema. Cabe mencionar que esas demostraciones físicas son recursos que dan sentido al conocimiento presentado y guían la construcción del conocimiento. Además, las preguntas y las explicaciones involucraron al estudiante en un proceso de razonamiento. De aquí que esta estrategia de la tutora flexibiliza "la transmisión del contenido y permite crear una zona de múltiples respuestas posibles donde se pueden establecer diferentes niveles de apropiación del contenido" (Candela, 1990, p. 19); asimismo, propició la construcción de una mirada relacional del contenido 
de la unidad de aprendizaje y las explicaciones de la tutora, y promovió la participación del niño conduciéndolo en la apropiación de ese conocimiento.

El ejemplo ilustra una de las varias relaciones tutoras que se construyen en una jornada de la clase en multigrado; pero, sobre todo, muestra la naturaleza compleja de las relaciones que se establecen entre los participantes y los conocimientos que movilizan. También se evidencian las distintas formas de interacción en torno a los textos y las interpretaciones que se construyen (Rockwell, 1995).

\section{REFLEXIONES FINALES}

El Modelo ABCD plantea el desarrollo de situaciones novedosas en las aulas: la elección de temas para abordar por parte de los alumnos, con ciertas limitaciones ya señaladas, pero que impulsan procesos de autonomía y de trabajo colectivo. El fomento del aprendizaje independiente, el desarrollo de competencias investigativas y de expresión oral y escrita, además de reconocer el valor de las ideas provenientes de múltiples actores, no solo las de los materiales educativos y docentes. Durante los procesos que sigue la implementación del Modelo no identificamos a alguna figura única poseedora del conocimiento: la mayoría de los participantes se involucraron en los procesos de enseñanza y aprendizaje, y durante éstos se desarrollaron procesos de negociación entre el tutor y el tutorado: el aula se convirtió en un espacio de cooperación y participación.

Sin embargo, el modelo podría ser reforzado en varios aspectos, tanto didácticos como en cuestiones materiales. Dentro de los primeros identificamos que ciertas prácticas se mantienen en las aulas como la copia de textos, el dictado, la enseñanza de la lectoescritura a través de estrategias alfabéticosilábicas y la exposición rutinaria de temas.

Habría que enfatizar a los docentes el que las redes de tutoría tienen un enorme potencial si se desarrollan entre alumnos de diversos niveles escolares y edades. Fueron pocas las observaciones realizadas donde alumnos de diversos niveles se tutorasen unos a otros. Estos procesos se enriquecerían al incluir a alumnos de diversos niveles educativos (preescolar y secundaria), lo cual podría fortalecer el trabajo colaborativo con profesores de otros centros escolares.

Con relación a la participación de familiares y demás miembros de las localidades, se podrían fortalecer dos aspectos en el desarrollo del Modelo: por un lado, el acercar a las aulas a los llamados conocimientos tradicionales, con el mismo valor que tienen los científicos. Por otro, se requiere mayor información de las implicaciones en el aula del Modelo ABCD hacia las madres y padres de familia. En contextos de baja escolaridad, cuando algunos de estos actores no visualizan que sus hijos realizan tareas tradicionales tanto en el aula, como en sus hogares a manera de tareas, los valoran como "un mal desempeño" del docente y generan la percepción que sus hijos no están aprendiendo. La participación de estos actores podría ir más allá que involucrarlos durante las Demostraciones, tal como se describió en la relación tutora desarrollada por la madre de familia. De esta manera, se facilitarían procesos de participación en las comunidades a través de relaciones 
horizontales entre los actores: "una participación colaborativa, con papeles flexibles y complementarios" (Rogoff et al., 2010, p. 108). Ello involucra el desarrollo de una gama de "interacciones compartidas entre múltiples miembros del grupo, con negociación de responsabilidades mutua y fluida y donde las decisiones se toman en consenso" (op. cit., p. 109).

Por último, es necesario que las autoridades inviertan mayores recursos económicos en estos proyectos educativos dirigidos a las poblaciones más pobres y marginadas del país, algo que no ha ocurrido desde hace décadas (véase Juárez y Rodríguez, 2016). Urrutia señala el que "una de las principales restricciones para el buen desempeño del CONAFE el origen contextual de sus alumnos, puesto que más de ocho de cada diez instructores trabajan en zonas de muy alta y alta marginalidad socioeconómica, y está junto con la baja escolaridad de las madres de familia" (2014, pp. 64- 65). Además, destaca que las pobres condiciones salariales de los LEC y la ausencia de prestaciones sociales dirigidas a ellos afectan los servicios educativos, sumado a "la marginalidad y las situaciones de riesgo que se viven en las comunidades en las que ellos laboran (...) Materiales educativos que no alcanzan a suplir la falta de competencias pedagógicas y didácticas" de los docentes.

Mejía y Martín del Campo (2016) señalan que durante el periodo 2009 a 2016 el presupuesto por alumno asignado al Conafe ha disminuido año con año hasta recibir 36\% menos en 2016, respecto a 2009. Mientras los Líderes de Educación Comunitaria sigan percibiendo apoyos económicos humillantes (actualmente el monto mensual equivale a $\$ 120$ dólares), la situación en las escuelas rurales mexicanas seguirá siendo muy desigual e inequitativa frente a otros contextos nacionales.

\section{REFERENCIAS BIBLIOGRÁFICAS}

Cámara, G. (2008). Otra educación básica es posible. México: Siglo XXI.

Cámara, G., Rincón, S., López, D., Domínguez, E. y Castillo, A. (2004). Comunidad de aprendizaje: Cómo hacer de la educación básica un bien valioso y compartido. México: Siglo XXI.

Candela, A. (2006). Del conocimiento extraescolar al conocimiento científico escolar: Un estudio etnográfico en aulas de la escuela primaria. Revista Mexicana de Investigación Educativa. (11) 30, 797-820.

Candela, A. (1990). Investigación etnográfica en el aula: el razonamiento de los alumnos en una clase de ciencias naturales en la escuela primaria. Investigación en la escuela. 11, 13-23.

Coll, C. (2004). Las comunidades de aprendizaje. Ponencia presentada en el IV Congreso Internacional de Psicología y Educación. Almería, España.

Coll, C. (2001, octubre). Las comunidades de aprendizaje y el futuro de la educación: el punto de vista del Fórum Universal de las Culturas. Documento presentado en el "Simposio Internacional sobre Comunidades de Aprendizaje". Barcelona.

Consejo Nacional de Fomento Educativo- Conafe (2017). Objetivos y Funciones de la Dirección de Educación Comunitaria e Inclusión Social. 
Recuperado de: https://www.gob.mx/conafe/acciones-yprogramas/direccion-de-educacion-comunitaria-e-inclusion-social

Consejo Nacional de Fomento Educativo- Conafe (2016). Unidades de Aprendizaje Autónomo. Pensamiento matemático. México: Consejo Nacional para el Fomento Educativo / Secretaría de Educación Pública.

Consejo Nacional de Fomento Educativo- Conafe (2012). Modelo de Asesoría Itinerante. México: Consejo Nacional para el Fomento Educativo.

Guerra, M. E. y O’Donnell, N. (2000). Educación Comunitaria. En Conafe. Equidad y calidad en la educación básica. La experiencia del CONAFE y la Telesecundaria en México. México: Consejo Nacional para el Fomento Educativo, 23-96.

Instituto Nacional para la Evaluación de la Educación- INEE (2016). Panorama Educativo de México 2015. Educación Básica y Media superior. México: Instituto Nacional para la Evaluación de la Educación.

Juárez, D. (2009). Educación rural en México: el caso de los cursos comunitarios. En García Horta, J. y Fernández Cárdenas, J. (eds.). Investigación, política y gestión educativa desde Nuevo León: Una aportación joven al debate nacional. México: UNESCO Comité Norte de Cooperación/ Universidad Autónoma de Nuevo León, 263-286.

Juárez, D. y Rodríguez Solera C. (2016, octubre). Factores que afectan a la equidad educativa en escuelas rurales de México. Pensamiento Educativo. (53) 2, 1-15.

Latapí, P. (2004). Prólogo. En G. Cámara, S. Rincón, D. López, E. Domínguez y Castillo, A. (eds.). Comunidad de aprendizaje: Cómo hacer de la educación básica un bien valioso y compartido. México: Siglo XXI, 9-11.

López, D., y Rincón, S. (2003). La capacitación artesanal en la formación de instructores. Posprimaria Comuniaria Rural del Conafe. Decisio. (5), 5054.

Mejía, F y Martín del Campo, A. (2016). CONAFE: una apuesta para la cobertura escolar y, ¿para la calidad educativa? Revista Latinoamericana de Estudios Educativos. XLVI (4) 51-64.

Mingorance, P. y Estebaranz, A. (2009). Construyendo la comunidad que aprende: la vinculación efectiva entre la escuela y la comunidad. Revista Fuentes, (9), 179-199.

Pieck, E. (2006). La Posprimaria Comunitaria Rural del CONAFE. En Caillods, F. y C. Jacinto (coords.). Mejorar la equidad en la educación básica: lecciones de programas recientes en América Latina. Paris: IIPEUNESCO, 83-163.

Rockwell, E. (1995). En torno al texto: tradiciones docentes y prácticas cotidianas. En Rockwell, E. (ed.). La escuela cotidiana. México: Fondo de Cultura Económica, 198-222.

Rogoff, B., Paradise, R., Mejía-Arauz, R., Correa-Chávez, M. y Angelillo, C. (2010). El aprendizaje por medio de la participación intensa en comunidades. En L. de León Pasquel (ed.). Socialización, lenguajes y culturas infantiles: estudios interdisciplinarios. México: CIESAS, 95-134. 
Procesos de enseñanza en escuelas rurales multigrado de méxico mediante comunidades de aprendizaje

Torres, R. M. (2001, octubre). Comunidad de aprendizaje: Repensando lo educativo desde el desarrollo local y desde el aprendizaje. Documento presentado en el "Simposio Internacional sobre Comunidades de Aprendizaje". Barcelona.

Turner, D. (2004). Reporte de la Evaluación. Posprimaria comunitaria rural. Mimeo.

Urrutia de la Torre, F. (2014). ¿Por qué los bajos resultados del Conafe en primaria? Restricciones para el buen desempeño del Consejo Nacional de Fomento Educativo. Revista Latinoamericana de Estudios Educativos. XLIV (1), 47-70. 
